\title{
Mother-infant separations in prison: Why does context matter?
}

Klare Martin and Claire Powell

\begin{abstract}
Mother-child separations are a gendered 'pain of imprisonment' leaving a legacy of further trauma for mothers on release, particularly those who are not reunited with their children. Building on Haney's (2005) contextual approach, this chapter will present a coproduced qualitative analysis of research findings on separated mothers in prison in England and Wales. This collaboration between a mother with lived experience of the prison system (Martin) and a prison researcher (Powell) will draw on feminist criminological work reflecting on personal experience of the prison system. Interweaving lived experience reflections with a study of maternal imprisonment, we discuss how imprisoned mothers' experiences of separation from their children are mediated by social support and wider systemic issues with the criminal justice system. Three aspects were emphasised by mothers and prison staff: 1) the impact of family relationships; 2) wider systems and agencies beyond prison; 3) prison mother and baby units (MBUs). We propose that a contextual understanding of mothers' experiences is needed to work towards mitigating the harms of mother-child separation.
\end{abstract}

Key Words: Prison mother and baby units, Family, Qualitative, Lived experience

\section{Introduction}

In March 2021 there were 3,116 women in prison (Ministry of Justice, 2021) and an estimated 17,500 children affected by maternal imprisonment in England and Wales (Kincaid, Roberts and Kane, 2019). There are 54 places for mothers and infants under 18 months on prison Mother and Baby Units (MBU), ${ }^{1}$ so most mothers will be separated from their children during their prison sentence. Mother-child separation needs

\footnotetext{
${ }^{1}$ Mother and Baby Units are separate areas of prison comprising individual rooms for mothers with their children and a nursery for group care. In England and Wales, there are MBUs in six of the twelve women's prisons (Sikand, 2015).
} 
consideration because of the enduring impact on mothers, children, and their caregivers during the prison sentence and beyond. Even short sentences result in disruption and harm for mothers and families (Masson, 2019).

Separation from children is one of the most traumatic aspects of imprisonment for women (Douglas, Plugge and Fitzpatrick, 2009, Corston, 2007), and relates to selfharm, risk of suicide (Independent Advisory Panel on Deaths in Custody, 2017), and mental health difficulties (Poehlmann, 2005). However, there are no centrally collected figures for the number of mothers in prison or children separated from their mothers (Galloway, Haynes and Cuthbert, 2014), although one estimate suggests that 60 percent of imprisoned women have children (Prison Reform Trust, 2019). For 85 percent of mothers, their prison sentence is the first time they are separated from their children (Caddle and Crisp, 1997), and only 5 percent of children with a mother in prison stay in their family home (Caddle and Crisp, 1997). Mothers can be separated from their children at different points through the criminal justice system (CJS): at arrest; at sentencing; at birth; or after time in a prison MBU. Children will be placed with family members (known as 'kinship care') or the state will take responsibility (Prison Advice and Care Trust, 2011). Some children will be adopted and never reunited with their families (Choices Islington, 2015).

The sentencing literature highlights where the issues around separation begin. This includes judges' lack of understanding of the damaging implications of mother- child separation, often emanating from stigmatising views of women in the CJS, and resulting in inconsistent sentencing practices (Minson et al., 2015; Minson, 2020). Research on magistrates shows similar problems (Birkett, 2016; Hedderman and Barnes, 2015) indicating how gendered social expectations influence sentencing practices and mothers' experience of the CJS. Building on this evidence, this chapter aims to understand imprisoned mothers' experiences of separation from their infants from a contextual theoretical perspective and consider how this might relate to the provision of peer support in prisons in England and Wales. Integrating lived experience reflections into a study of imprisoned mothers, the chapter presents an overview of the situation for 
imprisoned mothers and theoretical framework followed by Powell's research findings and Martin's reflections.

\section{Research with imprisoned mothers}

International scholarship on motherhood in prison is extensive (Enos, 2001; Lockwood, 2020; Shamai and Kochal, 2008) and underscores the challenging social contexts that mothers often face before imprisonment (Walker and Towl, 2016). Pregnant women face dehumanising experiences (Abbott et al, 2020), in addition to traumatic experiences of separation at birth (Chambers, 2009). Foreign national mothers must cope with separation from their children in a different country without additional support (Foley and Papadopoulos, 2013). The pain of separation does not end on release with ongoing shame for mothers (Baldwin, 2020).

Visitation is one key way that imprisoned mothers can keep in touch with their children, though mothers are reliant on children's carers for prison visits, including covering the travel costs and distances. In England and Wales rules around visits vary between prisons, however in general convicted prisoners are permitted two one-hour visits every four weeks (Crown Copyright, 2018); some prisons organise occasional 'family days' - longer visits with child-friendly activities (Partners of Prisoners, 2018). Booth's (2020) research on the experience of caregivers and their 'disenfranchised social status' highlights the stigma and the lack of support for families. Families affected by imprisonment are often socially disadvantaged and living in poverty (Jardine, 2018), and invisible in prison policy (Codd, 2013). The wider impact of imprisonment on families is described as the 'referred pains of imprisonment' (Lanskey et al., 2018).

The negative impacts of maternal imprisonment on children's physical and psychological health (Scharff Smith, 2014; Dallaire, Zeman and Thrash, 2015), and education (Trice and Brewster, 2004) are well-documented. A systematic review of the impact of parental imprisonment on children emphasises that the impact takes place in a wider context of disadvantage (Murray et al., 2009). However, there are specific 
stressors associated with maternal imprisonment. These include: witnessing a mother's arrest (Dallaire et al., 2015); prison visits (Poehlmann et al., 2010); the secondary stigmatisation associated with maternal imprisonment (Minson, 2019); and the adjustment period when a mother is released (McClure et al., 2015).

Some mothers remain with their children on MBUs, however they tend to be a less vulnerable group of women in comparison with the wider prison population with regards to their mental health and socio-economic backgrounds (Birmingham et al., 2006). Gregoire et al. (2010, p. 390) present data that show that separated mothers are at greater social disadvantage stating e that separation 'may contribute to or exacerbate the women's existing mental health problems and increase the negative effects on the child's current and future mental health'. The follow-up study by Dolan et al. (2013) found that after release, in comparison to MBU mothers, separated mothers remained socially disadvantaged with increased rates of unemployment, unsettled accommodation, homelessness and drug use.

Given the growing literature outlining the harms of maternal imprisonment, we suggest that separation from children should be understood as a 'pain of imprisonment'. Sykes' (1958) original conceptualisation of the 'pains of imprisonment' has since been developed from a gender-informed perspective (Genders and Player, 1990; Davidson and Chesney-Lind, 2009; Hannah-Moffat and Maurutto, 2010). Crewe et al (2017) coined the now widely used 'gendered pains of imprisonment' while Nuytiens and Jehaes (2020) discussed the more specific 'maternal pains of imprisonment' in their study of mothers in prison nurseries. We propose that taking a contextual approach to imprisonment and separation involves considering the harm caused by the prison context, and the social contexts of women in prison.

\section{Theoretical approaches: context, co-production, and peer support}

Arditti's $(2005,2012)$ analysis of parental imprisonment emphasises the interdependence of children, families, their contexts inside and outside of prison, and 
the social processes around imprisonment. With an intervention-based focus - in terms of the literature she draws on and the application of her framework - Arditti underlines 'the nature of harms due to incarceration' (2005, p.252) and how prisons should not cause more harm than the problems they are trying to solve. In a similar way, Haney's $(2005,2006,2020)$ contextual approach emphasises social historical and contextual factors as key influences, focusing on child abuse and neglect, poverty and inequality, racism, and institutional mistreatment as central to the context of imprisonment. In addition, 'prison life can be iatrogenic' (2020, p.196), in other words, re-traumatising. Like Arditti, Haney calls for prisons to be restructured to eliminate re-traumatisation (2020), because 'an unprecedented amount of pain has been inflicted in the name of crime control' (2006, p.30). As we have seen from the literature cited above , this is relevant when considering the impact of separation from children. Haney criticises person-centred thinking because it ignores the role of context in distress (2005:44), and suggests that 'prison itself can be seen as a powerful and potentially debilitating social context' (2005, p.48).

Whilst the empirical work presented in this chapter began from a contextual perspective, co-producing this work jointly between a prison researcher (Powell) and a mother with lived experience (Martin) meant that the framework was developed to incorporate relevant lived experience theories and literature around peer support. The inclusion of peer support is central as Martin draws upon her own experience of the CJS in order to offer support for imprisoned mothers in England and Wales through the charity Birth Companions $^{2}$, which in turn informed the research process. We were guided by Harding (2018) and Booth (2021) in our co-produced analysis. Harding $(2018 ; 2020)$ led us to reflect on whose perspective was privileged in the analysis. To ensure that Powell, with her lack of lived experience of CJS did not dominate, we wanted to privilege the women's narratives and used Martin's lived experience to guide our interpretation. Booth's (2021) work on 'trauma tourism' enabled reflection on language use and the

\footnotetext{
${ }^{2}$ Having met Birth Companions whilst I (KM) was in prison, I contacted them on my release to offer my support to other women going through the CJS. This was facilitated through a peer support programme devised to utilise the expertise of lived experiences, to better understand and support the complexities perinatal women face whilst in prison.
} 
avoidance of a 'stigmatising trauma discourse'. Booth highlights how the voices of experience can be used in a tokenistic way, as a way of illuminating painful stories but without working towards changing systems or practice. With this in mind, we considered how peer support might be improved by taking a contextual approach to enable us to use the painful experiences that women shared in a constructive way.

Bagnall et al (2015) carried out a systematic review of the effectiveness of peer support in prisons. The evidence was mixed, with limited empirical studies and most benefits for those delivering peer support. The peer support literature focuses on current prisoners delivering peer support (South et al., 2017), rather than former prisoners returning to prison as peer supporters. The most widely researched peer support scheme is the Samaritans' Listener ${ }^{3}$ scheme and, in one of the few studies with women, clear gender differences were found; women were more likely to seek help from and share with peers than men (Jaffe, 2012). Later research on the Listener scheme, and with women who self-harmed in prisons, found that women trusted other women more because they understood the gender-specific context around self-harm (Griffiths, Bailey and Slade, 2020). However, in a prison with a therapeutic community, ${ }^{4}$ women preferred receiving support from staff rather than peers for their self-harm because prisoner-staff relationships were more positive than in a mainstream prison (Griffiths, Bailey and Slade, 2019). This suggests that peer support must be considered in terms of the entire prison culture (South et al, 2017). However, further research on peer support for mothers in prison is required given that there is none thus far on perinatal women or mothers separated from their children. Using lived experience reflections to inform research findings could be a first step towards developing the research on peer support.

\footnotetext{
${ }^{3}$ The Listener scheme trains prisoners to support their peers who may be feeling suicidal. https://www.samaritans.org/how-we-can-help/prisons/listener-scheme/

${ }^{4} \mathrm{~A}$ therapeutic community is a group-based approach to mental health and substance use difficulties. See Richardson \& Zini (2021).
} 


\section{Methods}

This co-produced qualitative study aimed to explore the impact of context on imprisoned mothers' experiences of separation from their children. In response to the gaps in the literature, we developed the following research questions: 1) What are the contextual factors that affect imprisoned mothers' experiences of separation from their children?; 2) What are the implications for peer support with mothers separated from their children?

The interview data are drawn from a wider project that examined mother-infant separations in prison more broadly (Powell, 2018). Ethical approval for the original study was obtained from Middlesex University Psychology Ethics Committee and the National Offender Management Service National Research Committee. Two cohorts were recruited. First, six mothers, aged between 35 and 44 years were recruited through two community support organisations. The women had served sentences in four different prisons across England and their sentences ranged from nine months to seven years. The only criterion for inclusion was that a mother had been separated from her child aged under 11 years while serving a prison sentence. Second, twenty-four prison staff were recruited through two women's prisons. To take part, staff self-identified as supporting women separated from their children. Snowball sampling was used to reach staff from different professional backgrounds (healthcare, child and family-related services, prison officers). Over three quarters of the staff were aged over 35 years and over half had worked for more than five years ${ }^{5}$.

Following a workshop delivered by Powell on findings from the study, Martin wrote reflective notes related to imprisoned mothers' experiences of separation from their children. Powell carried out an initial framework analysis (Ritchie and Spencer, 1994) based on Martin's reflections. Martin and Powell discussed themes and interpretations to develop the final analysis. The findings in this chapter are accompanied by Martin's reflective commentaries (extending an approach used by Rains et al., 2021) on each key theme to show the resonances with her lived experience.

\footnotetext{
${ }^{5}$ For further details on staff and mother recruitment, including ethical considerations and the consent process, see Powell, 2018; Powell, Ciclitira and Marzano, 2020.
} 


\section{Findings}

We identified three key contextual factors that affected mothers' experiences of separation from their children. The factors external to prisons were 'Family relationships and support' and 'Wider systems and agencies'. The factor internal to prisons was 'Mother and baby units'. Figure 1 shows a representation of the three factors and their relationships to each other and pre- and post-prison contexts, based on Bronfenbrenner's (1977) ecological model ${ }^{6}$. The arrows reflect time and show that acceptance or rejection by an MBU is affected by the past and has an impact on the future.

Figure 1 - Three contextual factors affecting imprisoned mothers' separation from their children

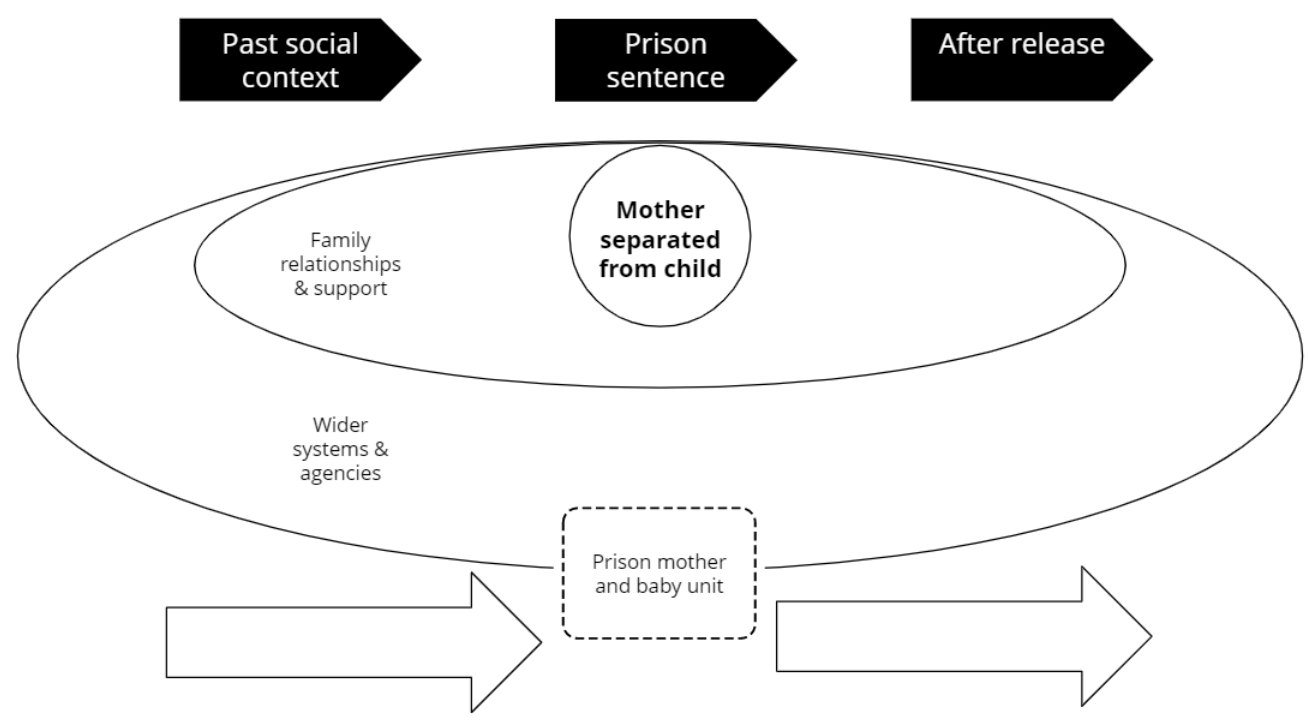

\section{Family relationships and support}

Family relationships were central to how mothers coped with separation from their children; alongside this was the perception of the quality of childcare provided by family

\footnotetext{
${ }^{6}$ Bronfenbrenner's theory is a way of understanding how different levels of a child's environment interact and have an impact. These levels include family, school and wider aspects of society and culture. Whilst initially used to study child development, the theory has since been applied more broadly.
} 
members. Mothers with supportive families who cared for their children were in a better position to cope with separation. Mothers whose families neglected their children suffered immensely from separation. One mother, Yvette, described the impact when her children came to visit and she realised they had been neglected:

"They came, l'll never forget. My children looked like shit. They were skinny. Their eyes were drawn in. I could say that they were undernourished...and I'll never forget it...that was the thing that broke me" (Yvette ${ }^{7}$, mother of two).

However, she was able to arrange for a friend to take over her children's care and this improved her experience of prison:

"It's like, my whole body, it's like something left me... It's just like the stress of everything had left me "(Yvette, mother of two).

Another mother explained that because she had no wider family support, she relied on one of her young adult children to care for her baby to prevent his removal into social care. This came at a cost:

"I would call my son at home...the bigger son looking after this little one, and I could hear how he was struggling and there's nothing I can do" (Chantelle, mother of two).

Chantelle described how the stress of worrying about both children and feelings of powerlessness led to severe distress throughout her prison sentence. Likewise, prison staff were aware of the negative impact on women without family support or with abusive family relationships. Staff gave examples of mothers who, following an MBU stay, were separated from their children on release from prison because they had no family support to help them manage the transition. A third sector organisation staff

${ }^{7}$ All names are pseudonyms 
member described her experience of working with mothers whose partners were abusive; in these cases, custody of children was by their violent fathers, who then prevented children's contact with mothers.

As these examples demonstrate, women's family contexts continue to affect them while they serve prison sentences and on release (Dodge and Pogrebin, 2001; Tasca, 2016). A lack of positive family support leads to a further disadvantage for mothers in prison and exacerbates the pains of imprisonment. This has implications both for understanding the impact of separation, and how and why peer support might be an alternative way to provide support, which is articulated in Martin's reflection below.

\section{Lived experience reflection}

On sentencing, being separated from my young child was distressing, especially not knowing when I would see him. However, I knew that he was well looked after by my husband and family, which comforted me. In the first few days, I tried not to think about my son too much as I knew it was the thing that could break me emotionally. Knowing he was okay allowed me to concentrate on myself during that separation, despite having the physical impact of producing unneeded breast milk as a constant reminder.

I am fortunate that my prison experience was a better one than most due to my family's support and understanding. It was easy to see the difference between myself (someone with exceptional support) and others (with little to no support). Mothers need both emotional and practical support; being without either can hinder a mother's ability to cope or care for her child. Having my family to speak to every night via telephone calls and seeing them twice a week on visits helped me to have some sense of normality. I continued to feel part of my family and I knew I could rely on them for both emotional and practical support.

Witnessing the extreme contrasts in external support was difficult to see but it motivated me to apply for a peer support programme in prison so I could support women who 
needed attention and emotional support. Being able to share that I was once where they are now, lifts women when they physically see there is life after prison, as well as reminding them that I am there for them.

\section{Wider systems and agencies}

Mothers and prison staff discussed the impact of wider systems on separation with children. The key agency was social services; social workers and foster carers both affected how mothers coped with separation. Annie described how her state of mind changed when her child was in temporary foster care and she and the foster carer had a positive relationship:

"No money can buy that sense of peace knowing that your baby is looked after when you're not there" (Annie, mother of one).

For other mothers, the relationship with their children was reliant on social services to organise visits. Leanne described her "sporadic" visits as "social services didn't go out of their way" to support her contact with her child and felt this had a long-term impact on their relationship.

Prison staff were aware of the challenges facing mothers regarding social services: they understood that mothers might avoid asking for help for fear of child removal (Prison officer). Staff expressed anger that social workers did not intervene when fathers prevented contact (Third sector worker), or when social services made last-minute decisions about separations at birth (Family worker). Overall, prison staff believed that separations were more traumatic with social services involvement (Prison officer), leaving prison staff to "pick up the pieces" (Third sector worker).

Apart from social services, mothers discussed the role of the court system, housing, and employment in child separations. Mothers explained that the stress of separation began before imprisonment, and then they faced ongoing or a new separation from their children on release. Before arriving in prison, Joy explained how the timing of her arrest 
and the court process meant she could not prepare her children for separation; whilst Leanne felt that judges "don't give a toss" about mothers, and so the implications are not considered in sentencing decisions (Minson, 2020). Annie described the impact of being housed in poor quality accommodation with her baby on release and her fears about losing custody as a result. Yvette felt that women needed support in prison for both council tenants and mortgage-holders, and she pointed out the difference in experience for men and women when released from prison:

"Different boroughs should have a team for women. I'm not disregarding men, but men get help, they have their mum, they have their aunt, they have their sister, they have their gran. Men always have women in their life. Women don't have no one. Women don't get help. Everyone thinks women and children get help. There is no help for them" (Yvette, mother of two).

As Dolan et al's (2013) study showed, separated mothers were more vulnerable on release and Leanne echoed this lack of services when she found that there was no drug rehabilitation service for her on release:

"I was in a hostel when I came out of prison. There's nothing put in place when you go into hostels. They should have all the services, like drugs and alcohol, but they don't. They deliberately put you into these places to set you up to fail". (Leanne, mother of seven)

Brenda felt that the lack of support from probation meant that "most people come out and don't have nowhere to go" (Brenda, mother of four), which in turn made child custody more difficult. Lack of support on release makes regaining child custody far more challenging (Gorden et al., 2020), often leaving mothers in vulnerable situations. Again, we see how wider systems and agencies have an important role to play in supporting mothers; this is the focus of Martin's next reflective piece. 


\section{Lived experience reflection}

On release I was not offered any support. I had to attend probation which is difficult as a mother when you have to find childcare; some probation officers are more understanding than others. At the time I did not know what was happening with my house, so I made contact with my local council. I was not entitled to any help and if I declared myself as homeless, all they could do was inform social services that my son was homeless and find somewhere for him to live without me and my husband.

Probation told me to speak to a specialist housing team and, although I had an initial conversation with them, I never heard from them again. Thankfully, in the end, I did not need housing help but the stark realisation that I could have been separated from my child was shocking and, at the time, extremely stressful.

There are charities that offer support, although you have to find them. I was fortunate to have been supported by Birth Companions ${ }^{8}$ during my sentence and I now work in the Lived Experience Team. This has given me the courage to voice my experience of the CJS as well as helping others going through similar experiences.
\end{abstract}

\title{
Prison mother and baby units
}

The final contextual factor significant in this study was access to prison MBUs. The units are a physical part of the immediate prison context however access to them is regulated by social services so they relate to mothers' relationships to wider systems and agencies (discussed above), their past histories before imprisonment and, as we shall discuss, their futures too.

In the interviews, both staff and mothers were preoccupied with who was excluded from MBUs. Staff pointed out that although in some prisons over half of women access drug and alcohol services, women using these services are not usually accepted onto MBUs. In the rare cases where a mother who needs these services does access an MBU, she

8 https://www.birthcompanions.org.uk/ 
is unable to access in-prison substance use support because of a lack of co-ordination between the MBU and in-prison services (Drug and Alcohol Service Manager).

As one mother pointed out, with support it is possible to address substance use difficulties and look after a baby. Annie explained that she was refused a place on a prison MBU however, on release, she accessed a community-based substance misuse MBU, which she credited with changing her life. Indeed, prison staff felt that women's histories had too much of an impact, without acknowledgement of what could have changed:

"I understand why you have to have strict criteria, but I don't think you should have criteria like, so-and-so once set fire to something. Everything should be risk assessed in that moment, taking into account the journey travelled" (Offender Manager).

This was echoed by Annie who felt everyone deserved an initial chance in an MBU "even people like me", in reference to her history of drug use:

"I don't think it feels fair for any woman. If there's like 60 people pregnant and only 12 can get a chance, it's not fair is it? The odds are stacked against them already" (Annie, mother of one).

This sense of unfairness about who is accepted into MBUs is reflected in the literature. Women on remand and serving short sentences are less likely to be accepted onto MBUs (Gregoire et al., 2010), which is problematic given how this applies to most imprisoned women (Ministry of Justice, 2021) ${ }^{9}$. However, it is the most socially disadvantaged women who are least likely to gain a place, including: women with repeated periods of imprisonment (Sikand, 2015); women with mental health difficulties and addiction problems (Birmingham et al., 2006); women who were unemployed

\footnotetext{
${ }^{9}$ On March $31^{\text {st }} 557$ women were remanded into custody; $62 \%$ of sentences for women were under 6 months (Prison Reform Trust, 2021).
} 
before being incarcerated (Birmingham et al., 2006). Exclusion has wider implications, with negative impacts on both the child and the mother's wellbeing, as well as increasing the likelihood that the mother may reoffend (O'Keefe and Dixon, 2015). It appears that wider social factors determine who will and who will not be separated from their young child, and both mothers and prison staff were acutely aware of this. Martin reflects on this having spent time in a prison MBU during her sentence.

\section{Lived experience reflection}

Throughout my time on the MBU, and since then during my peer support role, I have witnessed women with complex problems not getting places on MBUs. Many women with criminal convictions are victims and suffer from addiction and/or mental health problems. Support for these women is restricted on MBUs: drug and alcohol support groups and specialist care are held in the main prison making it difficult for women to attend. Staff managing MBUs are general prison staff without specific 'mother and baby' knowledge and lack specialised training to help support women with additional issues.

As a peer supporter I find that when I mention my prison experience, women engage. Often this happens with women labelled as 'difficult' who have repeatedly been failed by people in authority throughout their life. Knowing what prison is like, I can empathise and in turn, women open up about their feelings without fear of repercussions. Peer support is always woman-led; it is important to let women decide the level of support they want.

If the system could be changed, MBUs could support the individual needs and women who were once unlikely to get an MBU place could instead be given a chance. There is then a possibility that the cycles of re-offending could be broken. However, as it stands, we will never know as most women get rejected and the trajectory of their pained lives continue.

\section{Summary}

This chapter has demonstrated how separation from children is a 'pain of imprisonment' for women in prison, and especially for those who are already disadvantaged (Carlen, 
2013). The contextual analysis of data collected from interviews with imprisoned mothers and prison staff shows the unequal impact of separation from children: women who are more disadvantaged are more likely to be separated, more likely to have a worse experience of separation, and will be further disadvantaged on release. We propose that taking account of contextual differences in mothers' experiences of separation could help mitigate some of the harms of separation. Whilst there are limits to the support that can be offered in prisons, given the traumatising nature of the environment (Haney, 1997; Carlen, 2003; Maruna, 2011), awareness and provision of support for the impact of poor family support, prior social services involvement, and rejection from MBUs are concrete aims to have.

Furthermore, MBUs need to be accessible to more women. Many women cannot access MBUs for the very reasons that they are in prison, such as poverty and addiction (Carlen, 2013). Increasing MBU access should not be used as an excuse to imprison more women or to deflect resources from alternatives to imprisonment (Carlen, 2003). However, for women where prison is the only option, it is unethical to increase their pains of imprisonment and leave them further disadvantaged on release through separation from their children.

Moreover, we have shown how a contextual approach might explain why peer support is useful for imprisoned mothers separated from children. Women may be more likely to discuss their contextual disadvantages with peer supporters and peer supporters may be more likely to notice these disadvantages due to their own experiences. For peer supporters who are former, rather than serving prisoners, their distance from the prison setting (and its associated dynamics) coupled with their lived experience could provide something different to currently available programmes such as the Listeners. However, to ensure that this peer support was meaningful, programmes would ideally be designed and delivered by women with lived experience, and they would need to be paid appropriately for delivering this support. 
In conclusion, a contextual approach to separation from children for mothers in prison enables a nuanced understanding of the inequalities between women in prison. Whilst improvements can be made through applying this nuanced understanding, if we want to substantially reduce the harms caused by imprisonment, the primary focus needs to return to reduce the number of women in prison (Corston, 2007).

\section{References}

Abbott, L., Scott, T., Thomas, H. and Weston, K. (2020) 'Pregnancy and childbirth in English prisons: institutional ignominy and the pains of imprisonment'. Sociology of Health \& IIIness 42, 660-675.

Arditti, J.A. (2012) Parental Incarceration and the family. New York University, New York.

Arditti, J.A. (2005) 'Families and Incarceration: An Ecological Approach'. Families in Society $86,251-260$.

Bagnall, A.-M., South, J., Hulme, C., Woodall, J., Vinall-Collier, K. Raine, G., Kinsella, K., Dixey, R., Harris, L. and Wright, N.M.J. (2015) 'A systematic review of the effectiveness and cost-effectiveness of peer education and peer support in prisons'. BMC Public Health 15, 290.

Baldwin, L. (2020) 'A Life Sentence': The Long-term Impact of Maternal Imprisonment in K. Lockwood (ed.) Mothering from the Inside. Emerald Publishing: Bingley. pp. 85-104.

Birkett, G. (2016) "We have no awareness of what they actually do": Magistrates' knowledge of and confidence in community sentences for women offenders in England and Wales'. Criminology \& Criminal Justice, 16(4), 497-512. 
Birmingham, L., Coulson, D., Mullee, M., Kamal, M., and Gregoire, A. (2006) 'The mental health of women in prison mother and baby units'. Journal of Forensic Psychiatry and Psychology, 17, 393-404.

Booth, M. (2021) Michaela Movement [Blog]https://michaelamovement.com/ (Accessed: $20^{\text {th }}$ May 2021).

Booth, N. (2020) Maternal Imprisonment and Family Life. From the Caregiver's Perspective. Bristol: Policy Press.

Bronfenbrenner, U. (1977) 'Toward an experimental ecology of human development.' American Psychologist, 32(7), 513-531.

Caddle, D. and Crisp, D. (1997) Mothers in Prison (Research Findings No. 38) Home Office.

Carlen, P. (2013) 'Against rehabilitation: for reparative justice.' Criminal Justice Matters, 91(1), 32-33.

Carlen, P. (2003) 'Risk and Responsibility in Women's Prisons.' Current Issues in Criminal Justice, 15, 258.

Chambers, A.N. (2009) 'Impact of forced separation policy on incarcerated postpartum mothers.' Policy, Politics and Nursing Practice, 10, 207-11.

Choices Islington (2015) Choice for Change Annual report. London: Choices Islington. Codd, H. (2013) In the Shadow of Prison: Families, Imprisonment and Criminal Justice. Routledge.

Corston, B.J. (2007) The Corston Report. Home Office. 
Crewe, B., Hulley, S. and Wright, S. (2017) 'The Gendered Pains of Life Imprisonment.' The British Journal of Criminology 57, 1359-1378.

Crown Copyright (2018) Staying in touch with someone in prison.

Dallaire, D.H., Zeman, J.L., \& Thrash, T.M. (2015) ‘Children's Experiences of Maternal Incarceration - Specfic Risks: Predictions to Psychological Maladaptation.' Journal of Clinical Child \& Adolescent Psychology, 44(1), 109-122.

Davidson, J.T. and Chesney-Lind, M. (2009) 'Discounting Women: Context Matters in Risk and Need Assessment.' Crit Crim 17, 221.

Dodge, M. and Pogrebin, M.R. (2001) 'Collateral costs of imprisonment for women: Complications of reintegration.' The Prison Journal, 81(1), pp.42-54.

Dolan, R.M., Birmingham, L., Mullee, M., and Gregoire, A. (2013) 'The mental health of imprisoned mothers of young children: A follow-up study.' Journal of Forensic Psychiatry and Psychology, 24, 421-439.

Douglas, N., Plugge, E., and Fitzpatrick, R. (2009) 'The impact of imprisonment on health: What do women prisoners say?' Journal of Epidemiology and Community Health, 63, 749-754.

Enos, S. (2001) Mothering from the Inside: Parenting in a Women's Prison. SUNY Press.

Foley, L. and Papadopoulos, I. (2013) 'Perinatal mental health services for black and ethnic minority women in prison.' British Journal of Midwifery, 21, 552-562.

Galloway, S., Haynes, A., and Cuthbert, C. (2014) An unfair sentence. All babies count: Spotlight on the criminal justice system. NSPCC and Barnardos. 
Genders, E. and Player, E. (1990) 'Women lifers: Assessing the experience.' The Prison Journal, 70(1), pp.46-57.

Gorden, C., Lockwood, K., Madoc-Jones, I., Dubberley, S., Hughes, C., WashingtonDyer, K., Wilding, M.A. and Ahmed, A. (2020) 'Preventing homelessness among women prison leavers in Wales.' European Journal of Criminology, published online 16 Dec 2020. doi:10.1177/1477370820980433

Gregoire, A., Dolan, R., Birmingham, L., Mullee, M., and Coulson, D. (2010) 'The mental health and treatment needs of imprisoned mothers of young children.' Journal of Forensic Psychiatry \& Psychology, 21, 378-392.

Griffiths, L., Bailey, D. and Slade, K. (2020) ‘Exploring the listener scheme in a women's prison: the importance of a gendered approach to peer support for women who selfharm in custody.' The Journal of Mental Health Training, Education and Practice 15, 347-360.

Griffiths, L., Bailey, D. and Slade, K. (2019) 'Professional and peer support preferences for women who self-harm in custody.' Journal of Criminal Psychology 9, 109-121.

Haney, C. (2020) Criminality in Context. The psychological foundations of criminal justice reform. American Psychological Association, Washington DC, US.

Haney, C. (2006) Reforming Punishment: Psychological Limits to the Pains of Imprisonment. APA.

Haney, C. (2005) 'The contextual revolution in psychology and the question of prison effects.' In Liebling and Maruna (Eds). The Effects of Imprisonment. Willan Publishing.

Haney, C. (1997) 'Psychology and the limits to prison pain: Confronting the Coming Crisis in Eighth Amendment Law.' Psychology, Public Policy and Law, 3(4), 499-588. 
Hannah-Moffat, K. and Maurutto, P. (2010) 'Re-contextualizing pre-sentence reports: Risk and race.' Punishment \& Society 12, 262-286.

Harding, N. (2018) 'Places on probation: an auto-ethnography of co-produced research with women with criminal biographies.' In Plows. Messy Ethnographies in Action. Vernon Press.

Harding, N. (2020) 'Co-constructing feminist research: Ensuring meaningful participation while researching the experiences of criminalised women.' Methodological Innovations 13.

Hedderman, C. and Barnes, R. (2015) 'Sentencing women: An analysis of recent trends.' In Exploring sentencing practice in England and Wales (pp. 93-117). Palgrave Macmillan, London.

Independent Advisory Panel on Deaths in Custody [IAP] (2017) Preventing the Deaths of Women in Prison. DoH. Jaffe, M. (2012) Peer support and seeking help in prison: A study of the Listener scheme in four prisons in England. (Unpublished PhD thesis). Keele University.

Jardine, C. (2018) 'Constructing and Maintaining Family in the Context of Imprisonment.' British Journal of Criminology 58, 114-131.

Kincaid, S., Roberts, M. and Kane, E. (2019) Children of prisoners: Fixing a broken system. Crest, London.

Kruttschnitt, C. and Bijleveld, C. (2015) Lives of Incarcerated Women: An international perspective. Routledge. 
Lanskey, C., Losel, F., Markson, L. and Souza, K. (2018) 'Prisoners' Families, Penal Power, and the Referred Pains of Imprisonment.' In R. Condry and P. Scharff Smith (eds.) Prisons, Punishment, and the Family: Towards a New Sociology of Punishment? Oxford: Oxford University Press.

Lockwood, K. (ed). (2020) Mothering from the Inside. Bingley, UK: Emerald Publishing.

Maruna, S. (2011) 'Why Do They Hate Us?: Making Peace Between Prisoners and Psychology.' International Journal of Offender Therapy and Comparative Criminology, 55(5), 671-675.

Masson, I. (2019) Incarcerating Motherhood: The Enduring Harms of First Short Periods of Imprisonment on Mothers. Oxford: Routledge.

McClure, H.H., Shortt, J.W., Eddy, J.M., Holmes, A., van Uu, S., Russell, E., Koren, G., Sheeber, L., Davis, B., Snodgrass, J.J. and Martinez, C.R. (2015) 'Associations among mother-child contact, parenting stress, and mother and child adjustment related to incarceration.' In J. Poehlmann-Tynan (ed.) Children's Contact with Incarcerated Parents. (pp.59-82). Switzerland: Springer International Publishing.

Ministry of Justice (2021) Offender Management statistics quarterly, England and Wales.

Minson, S. (2019) 'Direct harms and social consequences: An analysis of the impact of maternal imprisonment on dependent children in England and Wales.' Criminology \& Criminal Justice 19, 519-536.

Minson, S. (2020) Maternal Sentencing and The Rights of the Child. London, UK: Palgrave Macmillan. 
Minson, S., Nadin, R. and Earle, J. (2015) Sentencing of mothers. Improving the sentencing process and outcomes for women with dependent children. Prison Reform Trust.

Murray, J., Farrington, D.P., Sekol, I. and Olsen, R.F. (2009) ‘Effects of parental imprisonment on child antisocial behaviour and mental health: a systematic review.' Campbell Systematic Reviews 5, 1-105.

Nuytiens, A. and Jehaes, E. (2020) 'When your child is your cellmate: The 'maternal pains of imprisonment' in a Belgian prison nursery.' Criminology \& Criminal Justice, published online 19 Sep 2020. doi: 10.1177/1748895820958452

O'Keefe, C. and Dixon, L. (2015) Enhancing Care for Childbearing Women and their Babies in Prison. Sheffield Hallam University.

Partners of Prisoners (2018) Prison Visitor Centre Services.

Poehlmann, J. (2005) 'Representations of attachment relationships in children of incarcerated mothers.' Child Development, 76, 679-696.

Poehlmann, J., Dallaire, D., Loper, A.B. and Shear, L.D. (2010) 'Children's contact with their incarcerated parents: research findings and recommendations.' American Psychologist, 65(6), 575-598.

Powell, C. (2018) Mother-infant separation in prison: Problematising attachment theory in policy and practice. (Unpublished PhD thesis). Middlesex University.

Powell, C., Ciclitira, K. and Marzano, L. (2020) 'Overwhelmed and powerless: staff perspectives on mother-infant separations in English prisons.' Journal of Criminal Psychology, 10(4), 311-328. 
Prison Advice \& Care Trust (2011) Protecting the welfare of children when a parent is imprisoned.

Prison Reform Trust (2019) Why focus on reducing women's imprisonment?

Prison Reform Trust (2021) Bromley Briefings Prison Factfile. Winter 2021.

Rains, L.S., Johnson, S., Barnett, P., Steare, T., Needle, J.J., Carr, S., Lever Taylor, B., Bentivegna, F., Edbrooke-Childs, J., Scott, H.R., Rees, J., Shah, P., Lomani, J., Chipp, B., Barber, N., Dedat, Z., Oram, S., Morant, N., Simpson, A. and the COVID-19 Mental Health Policy Research Unit Group (2021) 'Early impacts of the COVID-19 pandemic on mental health care and on people with mental health conditions.' Social psychiatry and psychiatric epidemiology, 56(1), pp.13-24.

Richardson, J. and Zini, V. (2021) Are prison-based therapeutic communities effective? Challenges and considerations. International Journal of Prisoner Health, Vol. 17 No. 1 , pp. $42-53$.

Ritchie, J. and Spencer, L. (1994) 'Qualitative data analysis for applied policy research.' In A. Bryman and R.G.Burgess (Eds.) Analyzing Qualitative Data (pp.173-194). London: Routledge.

Scharff Smith, P. (2014) When the Innocent are Punished. London: Palgrave Macmillan UK.

Shamai, M. and Kochal, R.-B. (2008) "'Motherhood Starts in Prison": The Experience of Motherhood Among Women in Prison.' Family Process 47, 323-340.

Sikand, M. (2015) Lost Spaces: Is the current procedure for women prisoners to gain a place in a prison Mother and Baby Unit fair and accessible? The Griffins Society. 
South, J., Bagnall, A.-M. and Woodall, J. (2017) 'Developing a Typology for Peer Education and Peer Support Delivered by Prisoners.' J Correct Health Care 23, 214229.

Sykes, G., (1958) The Society of Captives. Princeton, NJ: Princeton University Press.

Tasca, M. (2016) 'The Gatekeepers of Contact: Child-Caregiver Dyads and Parental Prison Visitation.' Criminal Justice and Behavior 43, 739-758.

Trice, A. D., \& Brewster, J. (2004) The effects of maternal incarceration on adolescent children. Journal of Police and Criminal Psychology, 19(1), 27-35.

Walker, T. \& Towl, G. (2016). Preventing Self-Injury and Suicide in Women's Prisons. East Sussex: Waterside Press. 